\title{
A potential pathway of coupled Si-C cycling driven by soil diatom growth associated with the weathering of Mg-bearing silicate minerals
}

\author{
Jing Su${ }^{1}$, Congqiang Liư ${ }^{1}$, Hui Henry Teng ${ }^{1, *}$
}

${ }^{1}$ Institute of Surface-Earth System Science, Tianjin University, Tianjin 300072, China (*correspondence: hteng@gwu.edu)

Silicon in the form of silicate minerals is the most abundant element (next to oxygen) in soils and can be mobilized through chemical/biological weathering. Once entering soil solutions, Si becomes a critical nutrient to take part in biochemical processes in plants and microbes exemplified by the wide occurrence phytoliths and the ubiquitous presence of diatoms near the surface of the Earth. The coupled biogeochemical cycling of Si and C on global scale is unambiguously demonstrated by the $\mathrm{Si}$ to $\mathrm{C}$ ratio in land plants $(0.02)$ and marine organisms (0.15), as well as by the estimated $\sim 1.5 \%$ and $\sim 4.5 \%$ contribution of Si-bioproduction to the overall primary production in terrestrial environment and coastal ocean [1].

The critical roles of microbes in silicate mineral weathering are well documented. However, how mineral substrates affect and control the microbial community remains to be elucidated. Literature data appear to suggest that minerals with different structures and chemical makeup can regulate microbial community development. If this is true, we suspect the metabolic activities as a feedback may influence local biogeochemical cycles. To test this hypothesis, we conducted field experiments in which different rock specimens (olivinite, basalt, gabbro, andesite, diorite, rhyolite, granite, dolomite, and limestone) were buried into soil for 48 days and examined upon retrieval for the microorganisms on each substrate. Sequencing results showed the microbial community exhibited significant differences between treatments at the end of experiments. First, the analysis of similarity (ANOSIM) showed a high R value of 0.78 and a $p$ value of 0.001. Among the different communities, we found the relative abundance of diatom was markedly upmediated in the treatment of olivinite, basalt, gabbro, and dolomite, while other treatments remained unchanged relative to that in the soil. Secondly, random forest analysis revealed diatom (a high Gini index of 1.25) plays a vital role in these up-mediating communities. In addition, chemical analyses revealed that bio-available Si concentration appeared to be the highest in the olivinite, basalt, gabbro treatment, while dissolved $\mathrm{Mg}$ was the most abundant in olivinite, basalt, gabbro, and dolomite treatment. On the basis that $\mathrm{Si}$ is an irreplaceable element for diatom to assemble its frustule and $\mathrm{Mg}$ is a core component for chlorophyll of alga, these findings prompted us to speculate that dissolution of Mg-bearing silicate minerals can preferentially promote the growth of diatom in soil microbial community. Given the close link between diatom growth and $\mathrm{C}$ cycle in soils, we propose a potential pathway for the coupled biogeochemical cycling of $\mathrm{C}$ and $\mathrm{Si}$ driven by the weathering of Mg-bearing minerals and the ensuing enhancement of diatom growth. Extending this possibility to global scale, it suggests that accelerated continental weathering at high atmospheric $\mathrm{pCO}_{2}$ conditions may lead to the bloom of diatoms that subsequently augments the coupled Si-C cycle to regulate the global $\mathrm{CO}_{2}$ level. If tested true, it may point to the importance of $\mathrm{Si}$ and $\mathrm{Mg}$ in keeping long-term climate stability over the geological history.

[1] Lerman, A., Li, D. D., \& MacKenzie, F. T. (2010). In AGU Fall Meeting Abstracts. 